Article

\title{
Institutional Commitment Problems and Regional Autonomy: The Catalan Case
}

\author{
Francesc Amat ${ }^{1, *}$ and Toni Rodon ${ }^{2}$ \\ ${ }^{1}$ Institutions and Political Economy Research Group, University of Barcelona, Spain; E-Mail: francesc.amat@ub.edu \\ 2 Department of Political and Social Sciences, Pompeu Fabra University, Spain; E-Mail: toni.rodon@upf.edu \\ * Corresponding author
}

Submitted: 14 June 2021 | Accepted: 21 September 2021 | Published: 10 December 2021

\begin{abstract}
This article examines what constitutional arrangements are more likely to facilitate the transfer of effective decision-making power to the regional level. We show that certain constitutional arrangements can result in institutional commitment problems between regional minority and national majority groups, which in turn influence levels of regional autonomy across regions. Specifically, we examine how the depth and scope of decentralization depend on the presence of federal agreements and the availability of institutional guarantees that make the federal contracts credible. Analyzing regional-level data, we show that regions where identity minority groups are majoritarian enjoy more regional autonomy when the commitment problem has resulted in a satisfactory national accommodation. Our findings highlight two important scenarios. The first occurs when the institutional commitment problem is solved, and regional minority groups are granted substantial levels of regional autonomy. The second scenario takes place when the commitment problem is not institutionally accommodated, and hence regional minority groups have systematically lower levels of autonomy. This article illustrates that both federal contracts and credible agreements are important tools to understand regional decision-making powers.
\end{abstract}

\section{Keywords}

commitment problem; fiscal autonomy; regional autonomy; sovereignty demands; territorial conflicts

\section{Issue}

This article is part of the issue "Secessionism in Liberal Democracies: What Do We Really Know About the Explanations of Secessionism?" edited by Ferran Requejo (Pompeu Fabra University, Spain) and Marc Sanjaume-Calvet (Pompeu Fabra University, Spain / Open University of Catalonia, Spain).

(C) 2021 by the authors; licensee Cogitatio (Lisbon, Portugal). This article is licensed under a Creative Commons Attribution 4.0 International License (CC BY).

\section{Introduction}

The recent Catalan-Spanish territorial crisis provides a good example of how a lack of a credible territorial agreement can lead to an escalation of political conflict. As has been reported elsewhere (Casas et al., 2021; Cuadras-Morató, 2016), the conflict largely stems from the Spanish Constitutional Court ruling in 2010 against several articles of the new Catalan Statute, approved both by the Catalan and the Spanish Parliament and by citizens in a referendum. Many in Catalonia perceived this ruling as a break-up of the territorial agreement between both parties. Consequently, the idea that ter- ritorial decentralization was no longer possible through constitutional arrangements and that the only alternative was secession started to gain hold.

The Catalan case is perhaps one of the most recent illustrative examples, but a look all over the world reveals that many current democracies still struggle to find a way to properly accommodate different economic, social, cultural, linguistic, or national realities (Abizadeh, 2021; Bednar, 2011; Beramendi \& Rogers, 2020). Political conflicts inside plurinational (or multi-ethnic) states often revolve around the distribution of effective policymaking between central and regional governments. Departing from this pattern, this article takes a fresh look at an 
old question and examines what types of constitutional arrangements are more likely to facilitate the transfer of effective decision-making power to the regional level. While the relationship between Catalonia and Spain is one of conflict and many Catalans still seek further autonomy, others like Wales-UK have found a way to settle on a degree of autonomy that satisfies an important part of the electorate. In some other contexts, like in Quebec (Canada), the Basque Country (Spain), or Northern Italy, territorial decentralization has recently increased and, as a result, the territorial demands have partially decreased in intensity. Overall, why are some regions granted more powers than others?

Against the backdrop of many existing explanations, essentially centered around identity-related factors (different language, culture, etc.) or the role of the economy (economic crisis, etc.), we put forward another explanation largely based on the credibility of territorial agreements between regional identity minorities and national majority groups. The transfer of effective decision-making power to regions, we argue, is contingent on the severity of the institutional commitment problem between the national majority group and the minority identity groups in advanced democracies (Abizadeh, 2021) - with the institutional commitment problem understood as the lack of a stable and credible institutional arrangement between the minority and the majority group. More specifically, we propose that in order to understand a region's level of territorial autonomy, one must take into account not only the presence of a federal agreement (decentralization), but also the credibility of this institutional agreement. In a nutshell, we argue that territorial decentralization should be higher in regions that have reached a federal agreement and where constitutional rigidity is sufficiently high as to bestow the agreement with enough credibility.

In contexts where regional minorities exist, the national majority group generally wants to reach an agreement so that minorities' territorial demands cease or are kept at a minimum. The majority group may also want to adopt a territorial model in which any potential secessionist aspirations by the minority group are avoided. In turn, the regional minority group wants to deepen levels of territorial decentralization. Yet, it also needs an important component largely neglected by previous work: a credible agreement. Any decision regarding the territorial organization of the state is likely to be implemented, even without the consent of national minorities. Therefore, without a credible federal pact, decentralization tends to be lower. As the Catalan case illustrates, the majority group can use its position and overturn the degree of autonomy given to the minority group. We posit that the credibility of a federal arrangement is manifested through the rigidity of the constitutionwhich essentially means the difficulty of reforming the constitution at the will of the majority group.

Our argument is tested using a dataset that contains information on the observed regional autonomy of differ- ent regions across different countries. The regional-level dataset, originally compiled by Sambanis and Milanovic (2014), is combined with Lijphart's dataset (Lijphart, 1999), which includes the degree of constitutional rigidity of different countries. The regional and cross-country information allows us to examine our theoretical intuition, that is, whether the degree of observed regional autonomy depends on the existence of a federal agreement and the credibility of the agreement through constitutional rigidity.

Our empirical results lend support to our theoretical intuition and reveal two scenarios of particular interest: In the first one there is a federal contract and the rigidity of the constitutional agreement is high. Under this scenario, regions tend to have high regional autonomy and, as a result of providing credibility to the system through rigidity, the minority group is granted relatively high levels of effective (fiscal) decision-making. The second scenario occurs when there is a federal contract, but constitutional rigidity is low, or when there is no federal contract, but constitutional rigidity is high. In both cases, the minority group is trapped in a situation in which it is not able to expand its regional autonomy, making the system unstable as the majority group can easily revert it.

\section{Theory}

The literature on territorial decentralization highlights three main groups of arguments explaining differences in levels of territorial autonomy across regions. A first group of studies emphasizes the idea that the choice to decentralize is a function of a country's territorial cultural heterogeneity. Thus, given the existence of a territorial cleavage (Lipset \& Rokkan, 1967), the institutional set-up is likely to reflect this reality. Needless to say, many countries also engage in a strategy of nationalization, that is, of adopting a single country's culture and making it the predominant one (Keating, 2014; Levene, 2000).

Since Lipset and Rokkan (1967), there has been a lively intellectual discussion regarding what specific institutional arrangements are most appropriate in societies with centre-periphery cleavages (plurinational societies). For instance, in his famous work on consociationalism, Lijphart (1999) defended that consociational institutions were able to satisfy the preferences of both the majority and the minority groups by having cabinets with grand coalitions and segmental territorial autonomy. Consocionalist theory has been debated and scrutinized extensively in previous work (see Andeweg, 2000). However, Lijphart's work has been hugely influential in providing a way to think about how minority and majority groups can coexist within a country. Similarly, the works by Lijphart (1999) and Elazar (1987) revolve around the idea that territorial decentralization, in the form of a federal arrangement, may be a powerful tool to appease the cultural demands made by minority groups. Also, Riker (1964) long strived to establish a general theory of federalism organized around the attempt 
to explain both the stability of the federal system and the accommodation of cultural groups. If we apply this idea to the example introduced above, it suggests that Catalonia was granted territorial autonomy as a way to accommodate its distinct culture, language, history, etc.

A second group of studies have employed a political economy approach and have examined the implications of political decentralization on economic outcomes. In particular, these studies have explored the impact of fiscal federalism on the distribution of governmental revenues and expenditures (or vice versa) and whether this distribution has an impact on various aspects of the economy, such as growth. According to this theoretical perspective, the degree of fiscal autonomy granted to the regions is largely a function of economic considerations (for instance, the idea that spending should be close to the region where it is executed). Importantly, a growing literature on fiscal federalism has shown that political federalism does not necessarily lead to fiscal decentralization and that the two types of decentralization may have different consequences for economic growth (Canaleta et al., 2004; Ezcurra \& Rodríguez-Pose, 2013; Lessmann, 2012; Rodríguez-Pose \& Ezcurra, 2011; Thornton, 2007). Along similar lines, we argue that the institutional provisions of political federalism affect the levels of fiscal federalism.

Extant literature focuses mainly on the effects of granting fiscal federalism on different outcomes, as well as on why fiscal autonomy has been granted in the first place. Rodden (2006) provides evidence that differences in countries' experiences with subnational fiscal discipline can in part be explained by differences in federal institutions. Sorens (2015) shows that central governments facing secessionist challenges try to hamstring regional tax collection. Applying this approach to the Catalan case, this would imply that fiscal autonomy was granted to the region due to economic considerations, such as increasing economic efficiency or an expected increase in economic returns. A version of the economic approximation has also tried to investigate whether territorial decentralization (or the demand for it) increases in the presence of economic shocks. However, this literature has not been conclusive (Bel et al., 2019; Cuadras-Morató \& Rodon, 2019). Overall, the economic approach has mainly studied what type of economic factors explain variation in fiscal autonomy granted to the regions or whether having more fiscal autonomy improves (or not) economic outcomes.

A third group of studies highlights that the observed differences in territorial decentralization across regions, countries, and over time is a function of political dynamics and especially of party competition. Early on, Riker (1964) suggested that the decentralization of political parties tends to precede administrative and fiscal decentralization (see also Garman et al., 2001). Its basic idea is that territorial decentralization is (at least partly) endogenous to the party competition dynamics triggered by the territorial set-up. For instance, some work shows that in a multi-layered territorial system, voters face difficulties in attributing responsibilities. This may incentivize political parties to increase their demands for further decentralization (or centralization).

Similarly, other work stresses that, in some contexts, political parties have incentives to emphasize issues on a second dimension of competition (the territorial one instead of the traditional left-right dimension) in order to garner political support. This results in a situation in which political parties strategically invoke the second dimension (the territorial dimension), expressing different opinions regarding the (re)decentralization dimension and trying to win votes by appealing to voters' preferences on this particular issue dimension (Amat, 2012). Applied to Catalonia, this explanation would imply that decentralization to the region was largely granted as a result of political competition, that is, because some regional parties had electoral incentives to demand further decentralization-and some national parties to grant it. Overall, and regardless of the mechanism suggested, the political competition idea is expressed in different forms, but it eventually points to the same outcome: that political competition is a crucial factor in shaping the territorial set-up of a country (Brancati, 2006, 2008; Massetti \& Schakel, 2016; Massetti \& Toubeau, 2020; Meguid, 2015; Toubeau \& Wagner, 2015; Verge, 2013).

\subsection{Institutional Commitment Problems and Regional Autonomy}

We complement the previous existing explanations and suggest a novel way to understand differences in autonomy across regions. Our argument is based on the logic of the commitment problem between the national majority group and the regional minority groups, and it can be seen as a way of combining previous approaches centered around the role of political competition and institutions. Our intuition builds on the notion that some form of territorial agreement (a combination of decentralization and recognition) explains differences in effective regional decision-making. Thus, we side with the institutional explanations and base our argument on the assumption that identity-related factors are not sufficient to fully account for variation in levels of regional autonomy, but that federal contracts are important tools in explaining this variation. However, we propose that the existence of a federal contract is not enough. In order to properly understand differences in regional autonomy, it is also crucial to take into account the credibility of territorial agreements.

In order to unpack this argument, we must consider the original conditions of these agreements. Territorial agreements (federal pacts) usually take place in a context in which there is a majority group and a minority group (or several minority groups). It is true that, in some contexts, like in Belgium, groups have similar sizes. However, the logic of our argument still applies to these contexts. 
These regional minority groups generally belong to different ethno-cultural groups than the majority, although this is not necessarily the case: There are many countries with federal agreements and a low (or absent) degree of national heterogeneity within the country. In any case, this federal arrangement (the federal pact) represents a foundational moment that grants decision-making powers to the region(s).

The territorial agreement, however, is clouded by an important tension, we argue, stemming from a commitment problem. A commitment problem occurs when actors cannot achieve their goals because of their inability to make promises or credible commitments. This common conceptual tool in game theory has also been most famously applied in the field of international relations and comparative politics to understand violence between two actors. Fearon (1995) argued that violence in Yugoslavia erupted because political communities found themselves without a third party that could guarantee agreements between them. In other words, and regardless of what the majority's leaders agree to, there is no solid guarantee that the leaders will not renege in the future using their majority status.

Although the context of territorial decentralization in Western democracies is a very different one, the commitment problem logic is still very much useful in order to understand under what conditions decision-making is more likely to be granted to the regions. Walter (2006) argues that ethnic groups are significantly more likely to seek self-determination if the government has acquiesced to an earlier group of separatists, and if the government is unlikely to encounter additional ethnic challengers in the future. However, her study focuses on scenarios of conflict, and therefore differs from ours. Thus, although territorial conflicts in democracies in the form of violence are also present-see for instance the recent Catalan case (Rodon \& Guinjoan, 2021)-these are less common and beyond the scope of this article.

Let us imagine a federal agreement between the majority and the minority group. Although an agreement has been reached, the majority group's first preference is still to keep as much power as possible, and at the same time avoid any potential destabilizing move from the minority group, such as a secessionist threat. Indeed, the majority group might fear that effective decisionmaking constitutes a slippery slope eventually leading to an increase in secessionist demands. In turn, the minority group oftentimes aspires to a certain degree of territorial decentralization. With no guarantee, the agreement constitutes an unstable one: The majority group can easily use its majority status to overturn the agreement. The minority group knows it and will have incentives to renege from the agreement. Therefore, there is a commitment problem.

Both the majority and the minority groups need a credible agreement-a commitment device to bestow credibility. That is, a guarantee that the federal agreement will not be overruled by the majority group in the future and that the minority group will maneuver within the system. The minority group seeks an institutional tool that limits the tyranny of the majority (Abizadeh, 2021). The institutional enforcement of credible guarantees is the essence of the commitment problem. This guarantee, we argue, is a crucial component of the federal agreement. If no mechanisms are established, the majority group may be tempted to impose a change in the federal agreement at some point in the future. In order to feel comfortable with the institutional set-up, the minority group needs a guarantee that the territorial agreement will not be overruled. If this condition is present, effective decision-making granted to the regions is likely to be higher and hence the "sweet spot" that satisfies both the majority and the minority group is more likely to be reached (Detterbeck \& Hepburn, 2018).

We suggest that the credibility of the federal contract-the commitment device-is mainly expressed through the rigidity of the constitutional system. Using the classical definition of Hirschman (1970), one could say that the majority group wants to exercise the voice, strengthen everyone's loyalty, and avoid any potential exit. Conversely, the minority group may be torn between loyalty and exit, but only if certain guarantees are met. The rigidity of the constitution has been shown to be an important factor constraining actors' behavior, and lending stability to the system (Lutz, 1994; Tsebelis, 2002). As explained by Sánchez-Cuenca (2010), the rigidity of a constitution enhances the credibility of the original (territorial) agreement. We argue that the same logic applies to the territorial set-up. When the territorial pact guarantees that the majority group will have its "hands tied" and will not reverse the territorial agreement unilaterally, the federal contract will be viewed as more credible. Therefore, we will observe higher levels of regional autonomy.

It is important to highlight that this process is based on the idea that any decentralization/autonomy is embedded in a constitutional rather than in a legislative framework. Although it is true that legislation can be changed more easily than constitutional (and territorial) agreements, the constitution ultimately determines the model of territorial decentralization. For instance, in the Catalan case, basic legislation can transfer (take back) competences to (from) regions, but the Spanish Constitution ultimately determines what type of competences can be transferred to regions, and the Spanish Constitutional Court interprets the legislation.

All in all, we argue that the credibility of the systemexpressed through constitutional rigidity-will enhance the loyalty between the majority and the minority groups. If territorial decentralization is coupled with rigidity providing institutional guarantees, we will tend to observe higher levels of regional autonomy. Yet, if the territorial decentralization is not coupled with rigidity, or the system is rigid without territorial decentralization, the regional autonomy will tend to be lower. Thus, our expectations are the following: 
Hypothesis 1: Regions where a minority group is majoritarian will have greater observed regional autonomy when the commitment problem is institutionally channeled with a federal contract and credible institutional guarantees.

Hypothesis 2: Regions in which the minority group' political demands for greater sovereignty are active will have greater regional autonomy when the commitment problem is institutionally sealed with a federal contract and credible institutional guarantees.

\section{Research Design}

In order to test our theoretical expectations, we employ a regional-level dataset that includes different regions across different democratic countries. The dataset captures differences in the levels of territorial decentralization, as well as in the degree of constitutional rigidity and the relative strength of national minorities. More concretely our database is a combination of the dataset created by Sambanis and Milanovic (2014) and that of Lijphart (1999). While the first one uses primary administrative sub-divisions (provinces, states, republics, departments) of decentralized countries as units of analysis, the second one captures different institutional characteristics at the country level. This set-up is appropriate for our empirical analysis, as it allows us to capture the dynamics of decentralization at the sub-national region as a function of country-wide institutional characteristics. In other words, if we had limited the analysis to countrylevel data, as much research in the field still does, we would be losing variation and even face the risk of not detecting meaningful empirical regularities.

Our outcome of interest measures the share of regional expenditure that can be financed out of regional revenues. The indicator comes from Sambanis and Milanovic (2014) and can be understood as a proxy for fiscal autonomy/independence. More specifically, it measures the percentage of revenues generated by regional political jurisdictions. Although other measures of regional autonomy are employed in the literature, such as the Regional Authority Index (Hooghe et al., 2016), we believe that the indicator created by Sambanis and Milanovic (2014) provides the best option for our empirical exercise, for several reasons.

First, other measures-most notably, the Regional Authority Index-are constructed by quantifying the degree of autonomy established in the articles on decentralization dictated by the laws - mainly constitutions or basic/general laws. Although this approach has advantages, it overlooks other important dynamics, such as the fact that other laws may provide a different view and change (often to undermine) the level of territorial decentralization. For instance, if one examines articles on decentralization in the 1978 Spanish Constitution, one might conclude that education is solely at the hands of the regions. However, any Spanish observer would quickly realize that this is far from the truth, as the central institutions, via other articles in the Constitution or general laws, have taken back some of the powers or have simply not transferred the competences. Instead, the indicator of the share of regional expenditure that can be financed out of regional revenues shows the degree of economic independence from the center, and thereby the degree of effective policymaking. Political autonomy is more meaningful if regions can finance expenditures out of their own revenues. In contrast, regions that spend a lot out of central government transfers are less independent from the central institutions. After all, the center might adjust the transfer amount and subsequently curtail regional autonomy. For a discussion, see Sorens (2015).

Second, the degree of observed regional autonomy (Sambanis \& Milanovic, 2014) is a more accurate indicator to test our theoretical expectations. Other indicators based on laws or constitutions generally show less variation over time. This is mainly due to the fact that, in many contexts, decentralization only translates into constitutional or legislative changes after a period of time. Instead, and since finances-and the financial transfers between the state and the regions and vice versa-are more malleable to the contextual situation, they are overall a good indicator of effective decisionmaking power, that is, of the degree of observed regional autonomy. Finally, economic and political measures of decentralization tend to be highly correlated. Table 1 shows the summary statistics of the different variables employed in our models.

We also employ several additional indicators-taken from the Sambanis and Milanovic (2014) dataset. First, a binary indicator identifying whether the region has a minority group (1) or not (0). This is based on the difference between the population living in a particular region vis-à-vis the other regions in the country. In other words, a region is considered to host an identity minority group if a national minority makes up more than $50 \%$ of the regional population. Second, a continuous indicator capturing the percentage of the largest identity group in the region that does not belong to the largest majority group in the country. And third, we use a binary indicator distinguishing regions where there is a political movement with active sovereignty demands (1) or otherwise (0). Thus, while the first two measures mainly capture the structural conditions of a region in a given country, the third one tackles the political dimension. Decentralization, and its political articulation, may exist due to the sheer existence of national minorities (proxied by the first two indicators) or to political dynamics (third one). The results section will examine all of them.

The degree of constitutional rigidity comes from Lijphart (1999). According to Lijphart, constitutional rigidity is seen as a central explanatory constitutional variable. In his view, rigidity is seen as an anti-majoritarian instrument while non-rigid constitutions without judicial review often lead to unrestricted majority rule. 
Table 1. Summary statistics.

\begin{tabular}{lcccc}
\hline Statistic & Mean & St. Dev. & Min & Max \\
\hline Observed regional autonomy & 0.61 & 0.31 & 0.00 & 1.34 \\
Lijphart's index of constitutional rigidity & 3.08 & 0.95 & 1 & 4 \\
Lijphart's index of federalism & 0.58 & 0.49 & 0 & 1 \\
National minority over 50\% & 0.14 & 0.35 & 0 & 1 \\
\% not belonging to majority group & 0.22 & 0.27 & 0 & 1 \\
Movement for greater sovereignty & 0.27 & 0.44 & 0.08 & 2.80 \\
Regional income vs. country's income & 0.93 & 0.32 & 0.00 & 18.5 \\
Relative regional population & 0.09 & 0.21 & 69.4 \\
Regional Gini index & 38.01 & 10.49 & & 1 \\
\hline
\end{tabular}

The indicator captures the array of amendment provisions on a four-point scale of rigidity, which ranges from 1 (amendment provisions are amended by an ordinary majority) to 4 (amendment proposals need more than a two-thirds majority or a two-thirds majority combined with other requirements, such as the approval by state legislatures).

On the other hand, the existence of a federal contract is also taken from Lijphart (1999). Specifically, we exploit Lijphart's index of political federalism 1945-2010. Although originally constructed as a continuous indicator, we have made it dichotomous to ease the interpretation of the results. The Supplementary File shows the results with the original indicator in its continuous form. The original index developed by Lijphart ranges between 1 and 5 , but we have coded the "Federalism" variable as a dummy variable that takes on the value 1 if the original Lijphart's index of political federalism is equal or greater than 4 and 0 otherwise. We do so because the original formulation of the Lijphart's federalism index is the following one: 1 for unitary and centralized nation-states, 2 for unitary but decentralized nation-states, 3 for quasifederal nation-states, 4 for federal but unitary states, and 5 for federal and decentralized states. In this original scale by Lijphart (1999), Spain receives the value 3 .

All in all, our dataset uses regions as our units of observation. These regions are clustered in different countries and therefore we exploit cross-regional variation in observed regional autonomy as a function of a country's characteristics. This implies that we exploit only cross-regional variation and not temporal variation. The dataset therefore includes one observation per region for the period from the mid-1990s to the early 2000s. The countries (and its regions) included in the analysis are: Argentina, Australia, Austria, Canada, France, Germany, India, Malaysia, Spain, Sweden, Switzerland, US, and the UK-those that are part of Lijphart's dataset. Although the number is small, there is enough variation both within and across countries in our variables of interest. More concretely, our empirical specification is based on the following form:

$$
\begin{aligned}
Y_{i j}= & \beta_{1} \text { Minority }_{i}+\beta_{2} \text { Minority }_{i} \times \text { Federalism }_{j} \\
& +\beta_{3} \text { Minority }_{i} \times \text { ConstRigidity }_{j}+\beta_{4} \text { Minority }_{i} \\
& \times \text { Federalism }_{j} \times \text { ConstRigidity }_{j}+\delta X_{i} \\
& +\gamma \text { CountryFEs }_{j}+\varepsilon_{i j}
\end{aligned}
$$

We estimate several models in which we regress observed regional autonomy at the regional level on the key institutional dimensions that determine the severity of the commitment problem. Most of our estimations include country Fixed Effects (FE). The inclusion of country FEs is important to control for unobserved countryspecific characteristics that might also affect regional autonomy. The main quantity of interest is the interaction term between the proxy for the existence of a minority group at the regional level and the two key dimensions of the commitment problem: the presence of a federal contract and constitutional rigidity. The estimations also include standard regional-level controls: regional per capita income relative to the country-wide income mean and the relative regional population as a share of the total country's population. Some models also include a measure of interpersonal inequality for each region. Finally, we adjust for the fact that some countries have more regions than others, and hence they could disproportionately influence the results, by using weights that are equal to the inverse of the number of regions in each country. The standard errors are clustered at the country level in all models.

\section{Results}

The results section presents the different sets of results in different steps. The first two tables employ two indicators tapping into the structural characteristics of the national minority groups. The third and final table focuses instead on the political side of the story, capturing the presence of political parties demanding sovereignty at the regional level. Table 2 presents our first results. The coefficient of interest comes from the interaction between the index of constitutional rigidity, the existence of a federal 
Table 2. Regional Autonomy, Commitment Problem, and Minority Dummy.

\section{(1)}

Minority Dummy
Constitutional Rigidity
X Minority Dummy

Minority Dummy

Constitutional Rigidity

$X$ Federalism $X$

Minority Dummy

$(0.06)$

-0.42
$(0.10)$

(0.81)

$0.48^{*}$
Federalism X

(2)

Observed Regional Autonomy

$-0.31 * *$

(0.10)

0.01

(0.07)

$-1.82^{* *}$

(0.23)

No
No
No
0.68
0.21
207

Regional Controls

Extended Regional Controls

Country FEs

Mean Dep. Var

$R^{2}$

$N$

Number of countries
11
$-1.03 * *$

$(0.40)$
(3)

Observed Regional Autonomy

$-0.21$

$-1.12^{*}$

(0.51)

Notes: Standard errors clustered at the country level in parentheses; Regional Controls: regional income, relative regional population; Extended Regional Controls: Gini; Main components of Federalism, Constitutional Rigidity, and Interaction included but not shown; $* p<0.10, * * p<0.05, * * * p<0.01$.

contract, and a minority group-the last two expressed as binary variables. As can be seen, the coefficient is positive and statistically significant. This means that the level of regional fiscal autonomy is positively related to the existence of high levels of constitutional rigidity and a federal agreement. Note, however, that this first approximation does not include country FEs.

Figure 1 eases the interpretation by visually displaying the different relationships of interest (based on Model 3). As advanced in our theoretical section, and looking at the right-hand panel, results show that the autonomy of a region is relatively high when there is a federal contract, high levels of constitutional rigidity, and the minority group is the majority in the region. Thus, given the presence of a minority group, regional autonomy tends to be larger when there is a federal agreement and high constitutional rigidity. Conversely, if there is a federal agreement and the credibility of the federal pact is low (low constitutional rigidity), a region's regional autonomy is significantly lower. The slope of the results in the right-hand panel in Figure 1 clearly indicates, as advanced in our theoretical discussion, that two conditions are needed in order to observe high levels of regional autonomy: high levels of constitutional rigidity and a federal contract.

Note that this also implies one striking and important initial finding: For minority regions, political federalism reduces fiscal federalism-at least in terms of local revenues generated by regional jurisdictions-and constitu- tional rigidity makes the effect of political federalism in minority regions less negative. This finding is coherent with the theoretical mechanism we propose-the institutional commitment problem. Under political federalism, constitutional rigidity seems to provide the institutional guarantees under which minority groups enhance their levels of fiscal autonomy.

Interestingly, if we look at the left-hand panel in Figure 1, the story is the opposite. When a federal contract is not present and a minority group is the majority in the region, this results in the minority group being trapped in a situation in which there are relatively low levels of regional autonomy. Under this scenario, the system is rigid and hence it is more difficult that the preferences of the minority group are properly accommodated. As a consequence, minority groups systematically enjoy less regional fiscal autonomy and this is exacerbated with greater constitutional rigidity.

In order to corroborate the theoretical expectations, we next run similar models, but in this occasion, we employ the minority size variable. Recall that the minority size variable takes into account the percentage of the largest group in the region that does not belong to the majority national group. While the previous indicator only considered the presence of a minority group (or not), this one adds more nuance and captures the potential "influence" the minority group has in each region. Also importantly, from now onward we include country-fixed effects to account for omitted institutional 

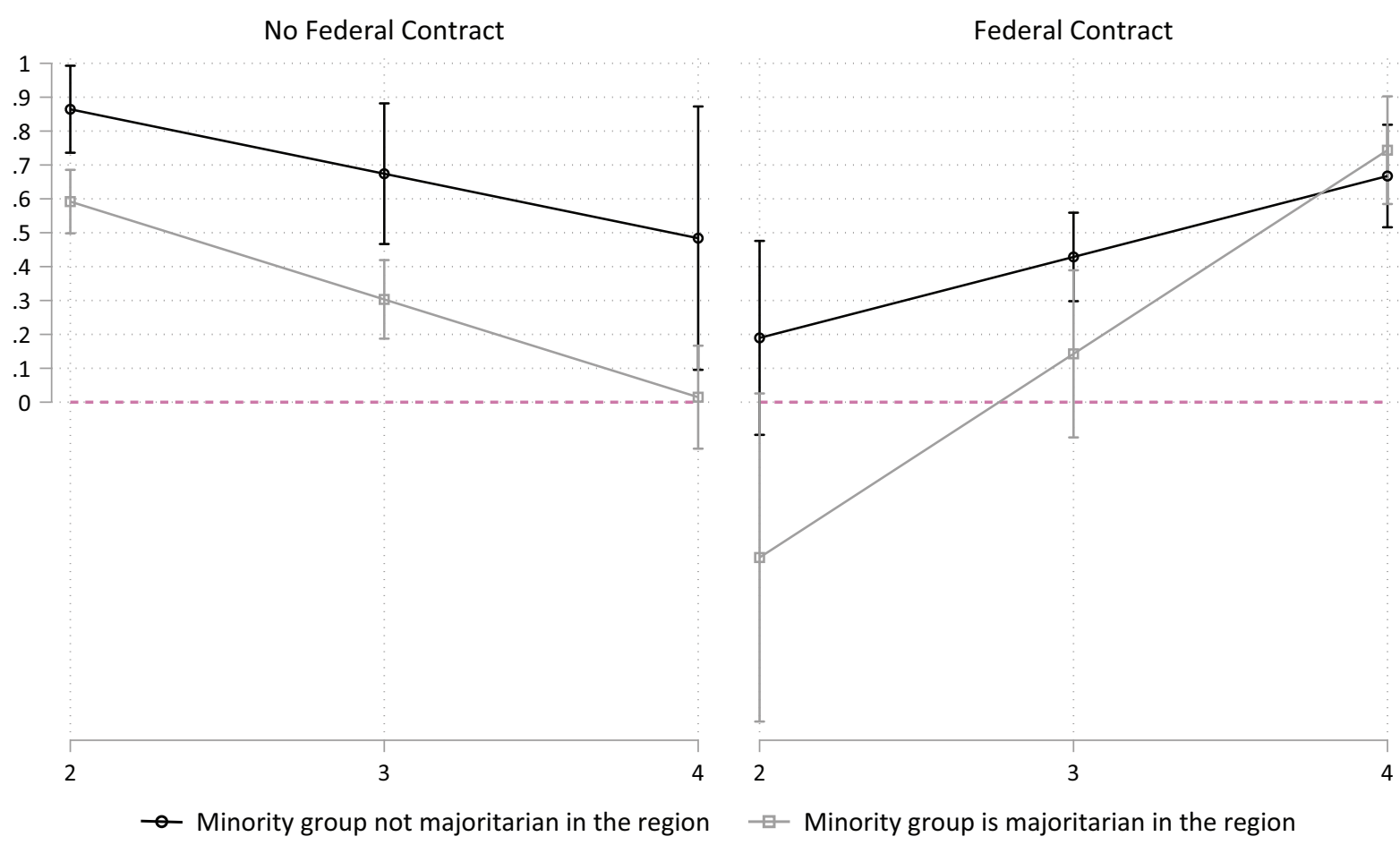

Figure 1. Predicted regional autonomy for minority groups, constitutional rigidity on the horizontal axis.

characteristics. Table 3 shows the results. As can be seen, the coefficient of interest, which is again the coefficient for the interaction term between constitutional rigidity, the federalism dummy, and minority size, is once again positive and statistically significant, very similar to the previous models. This implies that bigger regional minority groups only have access to higher levels of fiscal autonomy when two conditions are satisfied: political

Table 3. Regional Autonomy, Commitment Problem and Minority Size.

\begin{tabular}{|c|c|c|c|}
\hline & $\begin{array}{c}\text { (1) } \\
\text { Observed Regional } \\
\text { Autonomy }\end{array}$ & $\begin{array}{c}(2) \\
\text { Observed Regional } \\
\text { Autonomy }\end{array}$ & $\begin{array}{l}\text { (3) } \\
\text { Observed Regional } \\
\text { Autonomy }\end{array}$ \\
\hline Minority Size & $\begin{array}{l}0.65^{* * *} \\
(0.00)\end{array}$ & $\begin{array}{c}-0.97 * * \\
(0.39)\end{array}$ & $\begin{array}{l}-0.42 \\
(0.91)\end{array}$ \\
\hline \multicolumn{4}{|l|}{ Constitutional Rigidity } \\
\hline X Minority Size & $\begin{array}{l}-0.22 * * * \\
(0.00)\end{array}$ & $\begin{array}{l}0.18^{* * * *} \\
(0.05)\end{array}$ & $\begin{array}{c}0.03 \\
(0.23)\end{array}$ \\
\hline \multicolumn{4}{|l|}{ Federalism X } \\
\hline Minority Size & $\begin{array}{l}-1.95^{* * *} \\
(0.39)\end{array}$ & $\begin{array}{l}-1.11^{* * *} \\
(0.14)\end{array}$ & $\begin{array}{c}-1.46 * \\
(0.67)\end{array}$ \\
\hline \multicolumn{4}{|l|}{$\begin{array}{l}\text { Constitutional Rigidity } \\
\text { X Federalism X }\end{array}$} \\
\hline Minority Size & $\begin{array}{l}0.48 * * * \\
(0.13)\end{array}$ & $\begin{array}{l}0.33^{* * *} \\
(0.07)\end{array}$ & $\begin{array}{l}0.43^{* *} \\
(0.18)\end{array}$ \\
\hline Regional Controls & No & Yes & Yes \\
\hline Extended Regional Controls & No & No & Yes \\
\hline Country FEs & Yes & Yes & Yes \\
\hline Mean Dep. Var & 0.67 & 0.66 & 0.66 \\
\hline$R^{2}$ & 0.71 & 0.75 & 0.76 \\
\hline$N$ & 188 & 166 & 164 \\
\hline Number of countries & 9 & 8 & 8 \\
\hline
\end{tabular}

Notes: Standard errors clustered at the country level in parentheses; Regional Controls: Regional income, Relative Regional Population; Extended Regional Controls: Gini; ${ }^{*} p<0.10, * * p<0.05, * * * p<0.01$. 
federalism is coupled with enough constitutional rigidity to provide guarantees for such minority groups.

Figure 2 displays the marginal effects of the minority size indicator as a function of constitutional rigidity and the existence of a federal agreement. As can be seen, the positive slope once again confirms our intuition. When there is a minority group, a federal contract, and the level of constitutional rigidity is low, we tend to observe low levels of regional autonomy. In contrast, the autonomy granted to a region tends to be higher when both things are present-a federal arrangement and the credibility of the arrangement through constitutional rigidity. Overall, the last set of results confirm Hypothesis 1 . Note that Figure 2 confirms the striking result that we have discussed before: Regional identity minority groups systematically enjoy lower levels of fiscal autonomy under political federalism unless constitutional rigidity ameliorates the institutional commitment problem.

The final analysis goes a step further and aims to capture the effect of political demands for decentralization on the observed regional autonomy. While the first two indicators captured the structural characteristics of the majority-minority groups, one may wonder whether these characteristics may not be enough. In other words, the sheer presence of national minorities may not automatically imply that there should be demands for territorial decentralization. There needs to be, one could argue, political actors that bring the territorial demands to the fore. Many culturally distinct regions nowadays do not necessarily have regional parties pushing forward demands for decentralization.

With such a logic in mind, Table 4 replicates the analysis, but using a variable capturing the presence, or not, of a political actor with active sovereignty demands. The effect of the three-way interaction between constitutional rigidity, the existence of a federal contract, and the presence of an active sovereignty demand is again positive and statistically significant. Again, we encounter the same logic: Under political federalism, regional minority groups with sovereignty demands are constrained and more likely to have less fiscal autonomy unless constitutional rigidity is also present.

\subsection{Empirical Regularities and Implications for the Catalan Case}

To illustrate and summarize the main findings, Figure 3 presents the results. More specifically, Figure 3 shows the marginal effects of having political actors at the regional level actively demanding greater sovereignty on observed regional autonomy as a function of constitutional rigidity and the existence of a federal agreement. Looking at the right-hand panel in Figure 3, we see a clear upward slope. This means that, under a federal contract, politically active demands for sovereignty result in greater regional autonomy at the regional level (or at least not lower levels) as long as there is high constitutional rigidity. This is coherent with all the previous results: When regional actors demand greater sovereignty, constitutional rigidity facilitates regional autonomy if there is a federal contract. Interestingly, however, the slope reverses in the left-hand panel of Figure 3 when there is no federal agreement. When a federal contract is absent, sovereignty demands coupled with constitutional rigidity are systematically associated with lower levels of regional autonomy. It is remarkable

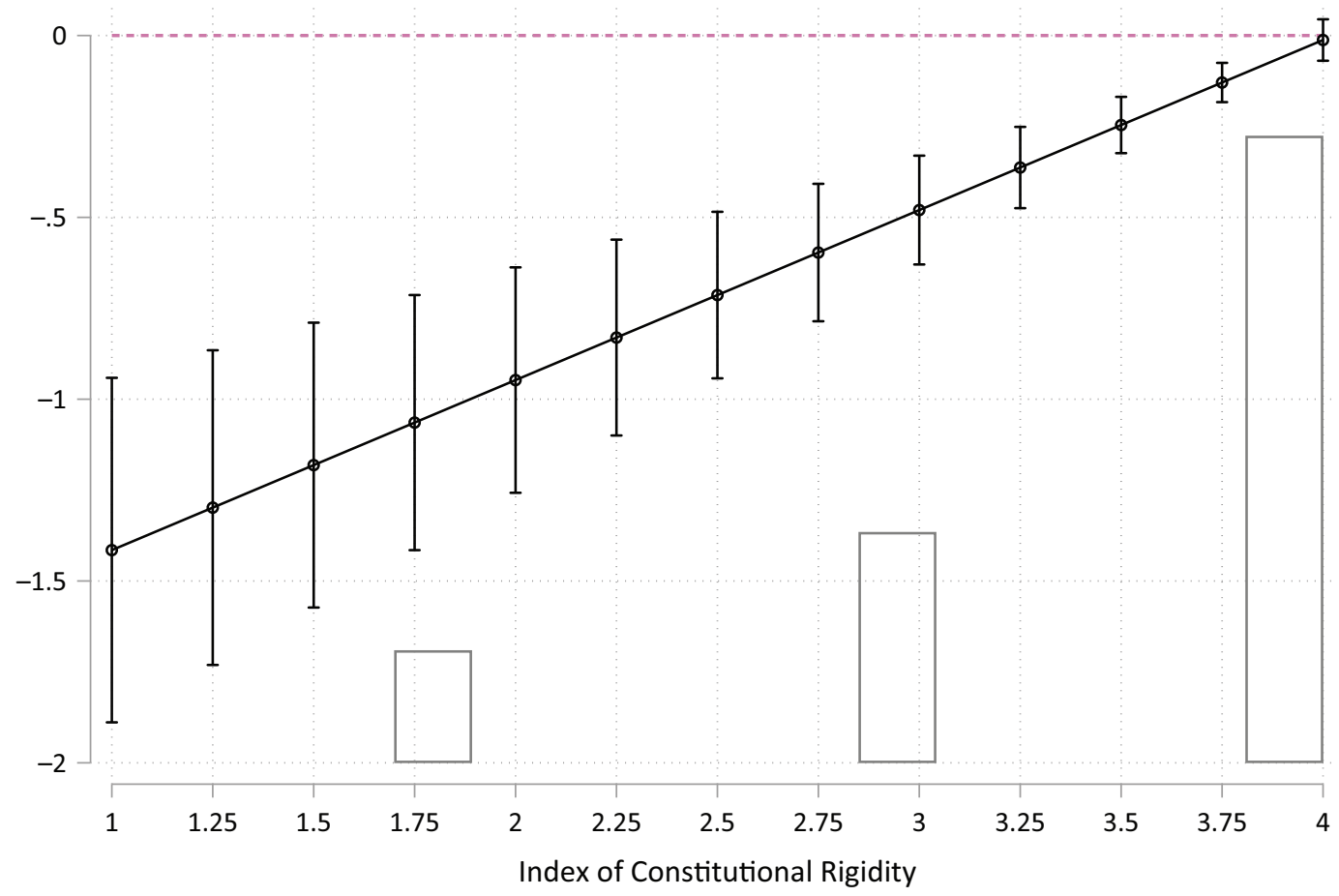

Figure 2. Marginal effects of minority size on regional autonomy as a function of federal contract and constitutional rigidity. 
Table 4. Regional Autonomy, Commitment Problem, and Sovereignty Demands.

\begin{tabular}{|c|c|c|c|}
\hline & $\begin{array}{c}\text { (1) } \\
\text { Observed Regional } \\
\text { Autonomy }\end{array}$ & $\begin{array}{c}(2) \\
\text { Observed Regional } \\
\text { Autonomy }\end{array}$ & $\begin{array}{c}\text { (3) } \\
\text { Observed Regional } \\
\text { Autonomy }\end{array}$ \\
\hline Sovereignty Demands & $\begin{array}{l}-0.03 \\
(0.03)\end{array}$ & $\begin{array}{c}0.17 \\
(0.13)\end{array}$ & $\begin{array}{c}0.17 \\
(0.13)\end{array}$ \\
\hline \multicolumn{4}{|l|}{ Constitutional Rigidity } \\
\hline X Sovereignty Demands & $\begin{array}{c}0.01 \\
(0.01)\end{array}$ & $\begin{array}{l}-0.07 \\
(0.06)\end{array}$ & $\begin{array}{l}-0.07 \\
(0.05)\end{array}$ \\
\hline \multicolumn{4}{|l|}{ Federalism X } \\
\hline Sovereignty Demands & $\begin{array}{l}-1.14^{* * *} \\
(0.35)\end{array}$ & $\begin{array}{l}-1.05^{* * *} \\
(0.20)\end{array}$ & $\begin{array}{l}-1.01^{* * *} \\
(0.20)\end{array}$ \\
\hline \multicolumn{4}{|l|}{$\begin{array}{l}\text { Constitutional Rigidity } \\
\text { X Federalism X }\end{array}$} \\
\hline Sovereignty Demands & $\begin{array}{l}0.31^{* *} \\
(0.11)\end{array}$ & $\begin{array}{l}0.30 * * * \\
(0.07)\end{array}$ & $\begin{array}{l}0.29 * * * \\
(0.07)\end{array}$ \\
\hline Regional Controls & No & Yes & Yes \\
\hline Extended Regional Controls & No & No & Yes \\
\hline Country FEs & Yes & Yes & Yes \\
\hline Mean Dep. Var & 0.71 & 0.70 & 0.70 \\
\hline$R^{2}$ & 0.72 & 0.73 & 0.74 \\
\hline$N$ & 247 & 222 & 220 \\
\hline Number of countries & 13 & 12 & 12 \\
\hline
\end{tabular}

Notes: Standard errors clustered at the country level in parentheses; Regional Controls: Regional income, Relative regional population; Extended Regional Controls: Gini; * $p<0.10, * * p<0.05, * * * p<0.01$.

to observe that the marginal effect of sovereignty demands on regional autonomy becomes negative when constitutional rigidity is high and there is no federal contact. It implies that regional minority groups are trapped in a scenario in which decentralization is low and rigidity is high, and, therefore, reforming the system is rather difficult for the regional minority group. The reversal of the slopes of the marginal effect of our binary indicator of sovereignty demands on observed regional autonomy are very much in line with the theoretical expectations based on the logic of the territorial commitment problem.

Finally, Figure 4 focuses on the role of having sovereignty demands by showing the overall predicted levels of regional autonomy as a function of having a federal contract (or not) and the degree of constitutional rigidity (horizontal axis). Crucially, we observe in both panels of Figure 4 that, when there are no active demands for sovereignty, the level of institutional rigidity or the existence of a federal agreement have a negligible effect on the degree of regional autonomy. Yet, when these demands are present, the institutional configuration of the federal arrangement is key in granting (or not) autonomy to the regions. Results in Figure 4 are also aligned with our theoretical intuition, hypothesized in Hypothesis 2. If a federal political contract is present and constitutional rigidity is high, the presence of sovereignty claims at the regional level results in relatively high levels of regional autonomy. In contrast, under a federal con- tract and low rigidity, the regional autonomy tends to be lower. On the left-hand panel of Figure 4 we also observe that the lack of a federal contract, coupled with rigidity, tends to result in low regional autonomy. In other words, regional political claims are associated with lower levels of regional autonomy when there is no federal agreement in place and constitutional rigidity is high.

We believe these findings have important implications, as the Catalan case illustrates. Spain was coded by Lijphart (1999) as a quasi-federal state and at the same time it is a country with relatively high levels of constitutional rigidity. According to the comparative empirical evidence we have presented, this puts the Catalan minority group in a position likely to have low levels of regional fiscal autonomy-as compared to alternative scenarios with a more complete federal deal coupled with institutional guarantees. As such, the institutional territorial commitment problem in Spain, which has, in line with current events, not been properly addressed, might be regarded as one of the key structural reasons behind the rise of secessionism in Catalonia (Casas et al., 2021). In this article, we have shown that the lack of a credible federal political contract makes regional minority groups less likely to enjoy fiscal autonomy. Very much in line with the argument in here, other recent research has underscored the role of information about the institutional design of inter-regional redistribution in shaping preferences for secession in the Catalan case (Hierro \& Queralt, 2021). 

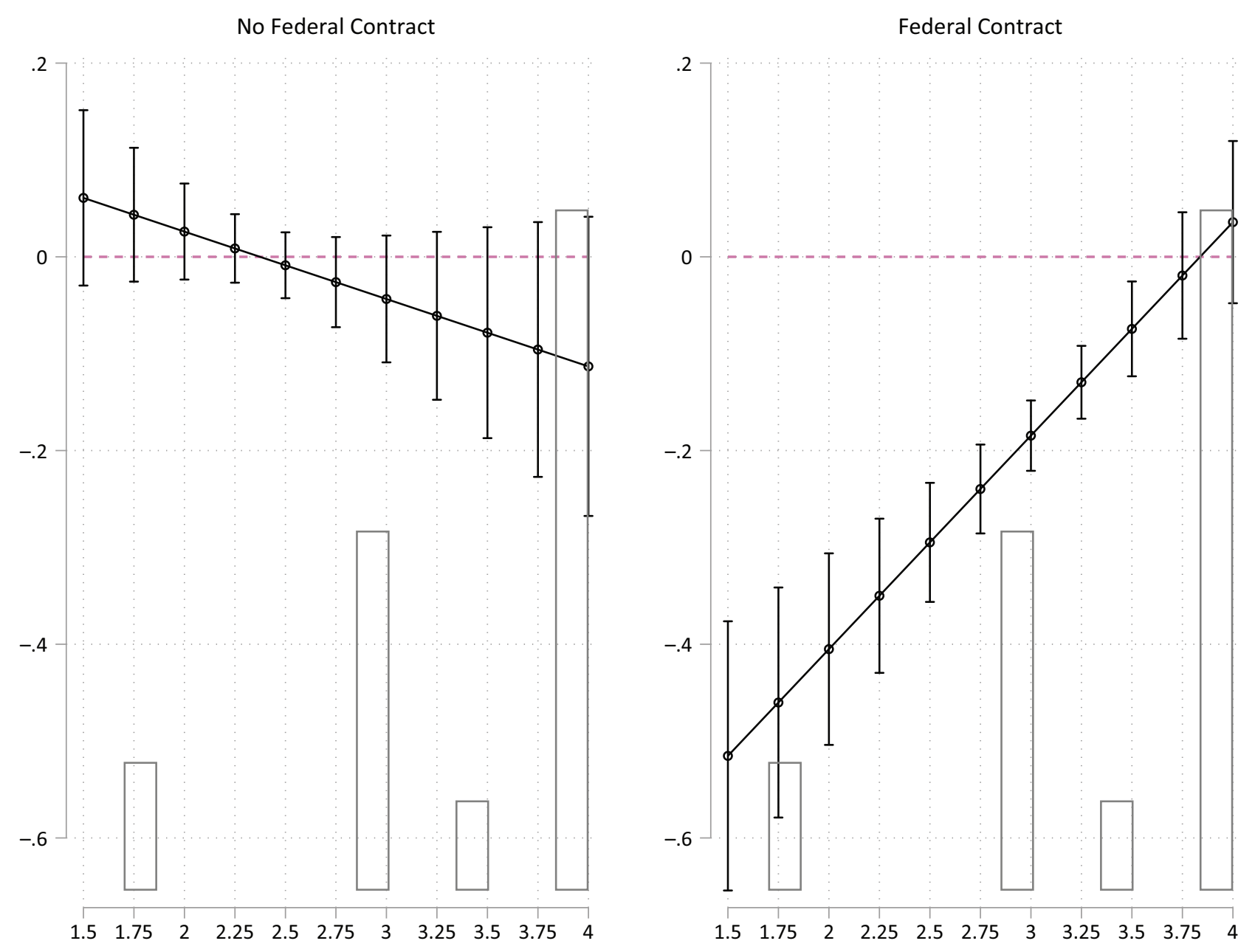

Figure 3. Marginal effects of sovereignty demands on regional autonomy, constitutional rigidity in the horizontal axis.
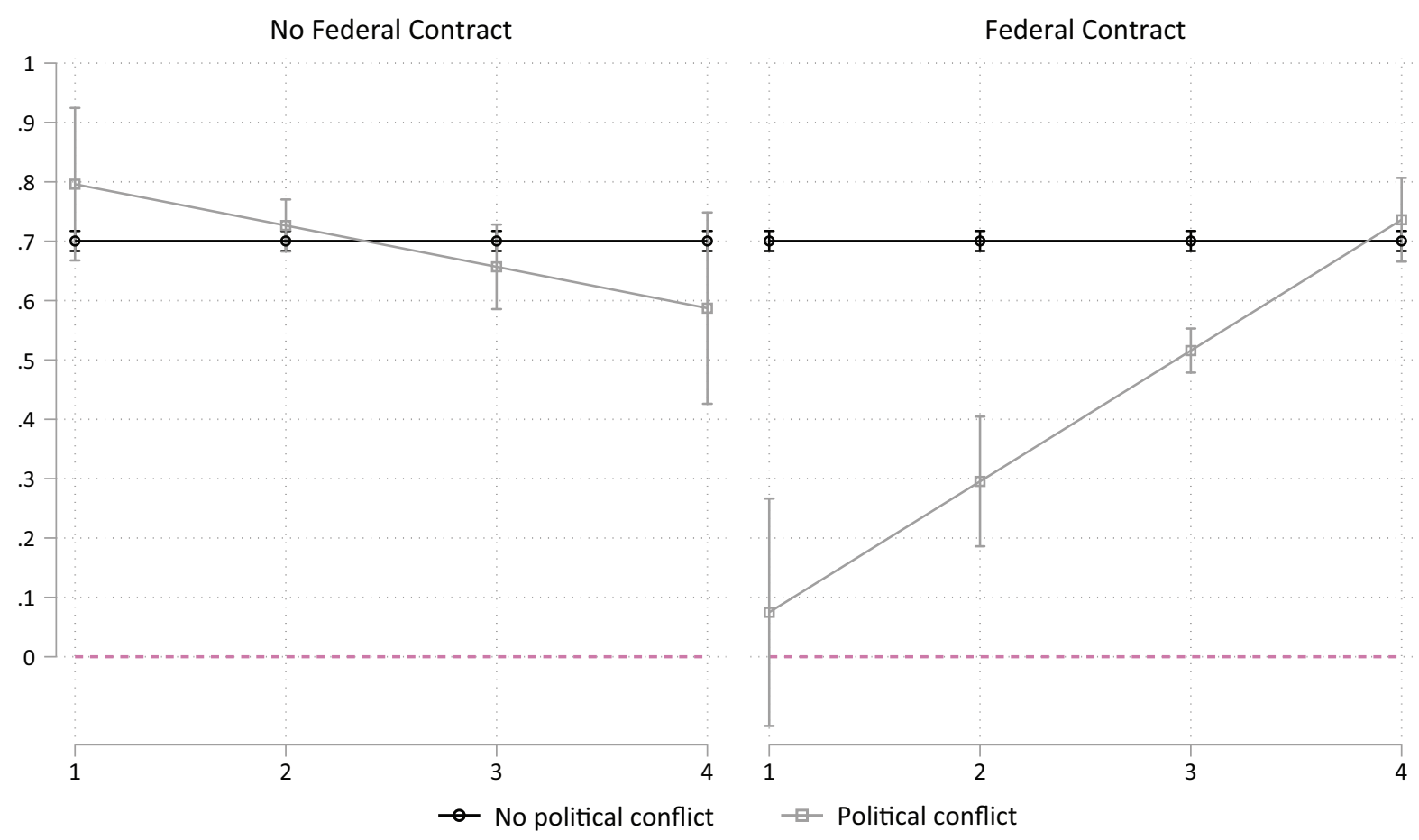

Figure 4. Predicted values of regional autonomy, constitutional rigidity in the horizontal axis. 


\section{Conclusions}

This article has advanced our understanding of what explains variation in political decentralization in several important ways. First, we have argued that existing explanations miss an important factor necessary to understand cross-regional variation in regional autonomy: the credibility of territorial agreements. A federal contract is not enough to guarantee a certain degree of decentralization. The majority and the minority group need to give credibility to the system and they do so through constitutional rigidity. Once both components are present, both the minority and the majority group are loyal to each other, exercise "voice" within the confines of the system and the probability of "exit" diminishes.

Second, we have shown that the logic behind institutional commitment problems is empirically correct and has important economic and political consequences. By exploiting a dataset that captures the degree of regional autonomy, as well as the status of the national minority and the rigidity of the constitutional text, we show that both are key factors in understanding the dynamics of the decentralization. Third, to be more specific, our results show that when there exists a federal agreement and the degree of constitutional rigidity is high, the level of regional autonomy tends to be higher. In contrast, a federal contract without constitutional rigidity, or constitutional rigidity without a federal contract, tend to lead to lower regional autonomy.

Overall, our results highlight two types of situations. The first scenario occurs when there is a federal contract and both the minority and the majority group have given credibility to the system via constitutional rigidity. In such a scenario, regional autonomy is high and the degree of decentralization is high. This scenario is one that can be observed in many federal countries nowadays, such as Germany or Switzerland. Scenarios in which the degree of decentralization is high (federal contract), the majority has its hands tied when it comes to unilaterally reforming the system, and the minority feels comfortable within the system as it enjoys a high degree of autonomy and the tyranny of the majority does not prevail (Abizadeh, 2021). This scenario should be associated with fewer territorial demands and fewer secessionist claims (Gibilisco, 2021).

The second model has different versions, but they share the important characteristic that they result in lower decision-making for the regions. They occur when there is a federal contract, but the constitutional rigidity is low; or when the constitutional rigidity is high, but the federal contract is absent. In such situations, the observed outcome is the same: Regional autonomy is low. Most importantly, the minority and the majority group are trapped in a scenario in which territorial demands are likely to persist. For instance, if there is no federal contract and high constitutional rigidity, some sub-state regions may demand higher autonomy, but the prospects of obtaining it are low since the majority group will tend to block it. This is, for instance, the case of Catalonia in Spain, where any territorial agreement needs the consent of the majority group and where the majority group can overturn important arrangements. In this situation we should expect a much greater prevalence of territorial demands.

We believe our results are important for our understanding of the dynamics of territorial decentralization and secessionist claims. Much previous work has addressed the issue by examining levels of decentralization. However, we have argued, and shown, that the credibility bestowed to the system is an important component to be taken into account. In other words, the territorial conflict cannot solely be addressed via decentralization measures, but through mechanisms that enhance the credibility of the institutional agreements and make it easier for both the majority and the minority group to coexist in the future. The lack of institutional guarantees, or the perception of its absence by regional minority groups, can explain the oftentimes puzzling non-linear relationship that we observe between decentralization and the emergence of territorial demands.

\section{Acknowledgments}

We would like to thank Alejandra Suarez and Emmy Lindstam for excellent research assistance.

\section{Conflict of Interests}

The authors declare no conflict of interests.

\section{Supplementary Material}

Supplementary material for this article is available online in the format provided by the authors (unedited).

\section{References}

Abizadeh, A. (2021). Counter-majoritarian democracy: Persistent minorities, federalism, and the power of numbers. American Political Science Review, 115(3), 742-756.

Amat, F. (2012). Party competition and preferences for inter-regional redistribution in Spain. South European Society and Politics, 17(3), 449-465.

Andeweg, R. B. (2000). Consociational democracy. Annual Review of Political Science, 3, 509-536.

Bednar, J. (2011). The political science of federalism. Annual Review of Law and Social Science, 7(1), 269-288.

Bel, G., Cuadras-Morató, X., \& Rodon, T. (2019). Crisis? What crisis? Economic recovery and support for independence in Catalonia. Regional Science Policy \& Practice, 11(5), 833-848.

Beramendi, P., \& Rogers, M. (2020). Fiscal decentralization and the distributive incidence of the Great Recession. Regional Studies, 54(7), 881-896. 
Brancati, D. (2006). Decentralization: Fueling the fire or dampening the flames of ethnic conflict and secessionism? International organization, 60(3), 651-685.

Brancati, D. (2008). The origins and strengths of regional parties. British Journal of Political Science, 38(1), 135-159.

Canaleta, C. G., Pascual Arzoz, P., \& Rapun Garate, M. (2004). Regional economic disparities and decentralisation. Urban Studies, 41(1), 71-94.

Casas, A., Curci, F., \& de Moragas, A. (2021). Checks and balances and nation building: The Spanish Constitutional Court and Catalonia. Society for Institutional \& Organizational Economics. https://extranet.sioe.org/ uploads/sioe2020/casas_curci_de-moragas.pdf

Cuadras-Morató, X. (2016). Catalonia: A new independent state in Europe? A debate on secession within the European Union. Routledge.

Cuadras-Morató, X., \& Rodon, T. (2019). The dog that didn't bark: On the effect of the Great Recession on the surge of secessionism. Ethnic and Racial Studies, 42(12), 2189-2208.

Detterbeck, K., \& Hepburn, E. (Eds.). (2018). Handbook of territorial politics. Edward Elgar Publishing.

Elazar, D. J. (1987). Exploring federalism. University of Alabama Press.

Ezcurra, R., \& Rodríguez-Pose, A. (2013). Political decentralization, economic growth and regional disparities in the OECD. Regional Studies, 47(3), 388-401.

Fearon, J. D. (1995, August 30-September 2). Ethnic war as a commitment problem [Paper presentation]. Annual Meetings of the American Political Science Association, New York, USA. http://pscourses.ucsd. edu/poli120n/Fearon1995.pdf

Garman, C., Haggard, S., \& Willis, E. (2001). Fiscal decentralization: A political theory with Latin American cases. World politics, 53(2), 205-236.

Gibilisco, M. (2021). Decentralization, repression, and gambling for unity. Journal of Politics. Advance online publication. https://doi.org/10.1086/711626

Hierro, M. J., \& Queralt, D. (2021). The divide over independence: Explaining preferences for secession in an advanced open economy. American Journal of Political Science, 65(2), 422-442.

Hirschman, A. O. (1970). Exit, voice, and loyalty: Responses to decline in firms, organizations, and states. Harvard University Press.

Hooghe, L., Marks, G., Schakel, A. H., Chapman Osterkatz, S., Niedzwiecki, S., \& Shair-Rosenfield, S. (2016). Measuring regional authority: A post-functionalist theory of governance. Oxford University Press.

Keating, M. (2014). Introduction: Rescaling interests. Territory, Politics, Governance, 2(3), 239-248.

Lessmann, C. (2012). Regional inequality and decentralization: An empirical analysis. Environment and Planning A: Economy and Space, 44(6), 1363-1388.
Levene, M. (2000). The limits of tolerance: Nation-state building and what it means for minority groups. Patterns of Prejudice, 34(2), 19-40.

Lijphart, A. (1999). Patterns of democracy. Yale University Press.

Lipset, S. M., \& Rokkan, S. (1967). Party systems and voter alignments: Cross-national perspectives. Free Press.

Lutz, D. S. (1994). Toward a theory of constitutional amendment. American Political Science Review, 88(2), 355-370.

Massetti, E., \& Schakel, A. H. (2016). Between autonomy and secession: Decentralization and regionalist party ideological radicalism. Party Politics, 22(1), 59-79.

Massetti, E., \& Toubeau, S. (2020). The party politics of territorial reforms in Europe. Routledge.

Meguid, B. M. (2015). Multilevel elections and party fortunes: The electoral impact of decentralization in Western Europe. Comparative Politics, 47(4), 379-398.

Riker, W. H. (1964). Federalism: Origin, operation, significance. Little, Brown and Company.

Rodden, J. A. (2006). Federalism. In A. D. Wittman \& B. R. Weingast (Eds.), The Oxford handbook of political economy (pp. 357-372). Oxford University Press.

Rodon, T., \& Guinjoan, M. (2021). Beaten ballots: Political participation dynamics amidst police interventions. Political Science Research and Methods. Advance online publication. https://doi.org/ 10.1017/psrm.2020.48

Rodríguez-Pose, A., \& Ezcurra, R. (2011). Is fiscal decentralization harmful for economic growth? Evidence from the OECD countries. Journal of Economic Geography, 11(4), 619-643.

Sambanis, N., \& Milanovic, B. (2014). Explaining regional autonomy differences in decentralized countries. Comparative Political Studies, 47(13), 1830-1855.

Sánchez-Cuenca, I. (2010). Más democracia, menos liberalismo [More democracy, less liberalism]. Katz Editores.

Sorens, J. P. (2015). Secession risk and fiscal federalism. Publius: The Journal of Federalism, 46(1), 25-50.

Thornton, J. (2007). Fiscal decentralization and economic growth reconsidered. Journal of Urban Economics, 61, 64-70.

Toubeau, S., \& Wagner, M. (2015). Explaining party positions on decentralization. British Journal of Political Science, 45(1), 97-119.

Tsebelis, G. (2002). Veto players: How political institutions work. Princeton University Press.

Verge, T. (2013). Party strategies on territorial reform: State-wide parties and the state of autonomies in Spain. West European Politics, 36(2), 317-337.

Walter, B. F. (2006). Information, uncertainty, and the decision to secede. International Organization, 60(1), 105-135. 


\section{About the Authors}

Francesc Amat is a Ramon y Cajal fellow at the University of Barcelona. He is also the deputy director of the Institutions and Political Economy Research Group. His main research interests are comparative politics and political economy. https://sites.google.com/site/cescamat

Toni Rodon is an assistant professor at the Department of Political and Social Sciences at the Pompeu Fabra University. His main research interests are political behavior, comparative politics, and political geography. https://www.tonirodon.cat 